\title{
CATSPER CALCIUM CHANNELS IN HUMAN SPERMATOZOA AND THEIR ROLE IN RESPONSIVENESS TO PROGESTERONE (P).
}

Tamburrino L, Marchiani S, Cambi M, Muratori M, Forti G, Baldi E.

Dept. of Biomedical Experimental and Clinical Sciences, University of Florence, Florence, Italy.

CATSPER is a family of sperm-specific calcium channels activated by $P$ in human spermatozoa, and indicated as putative $P$ sperm receptors (Strunker et al, 2011; Lishko et al, 2011). KO mice for CATSPER channels are infertile due to severe defects in sperm motility. The aim of this study is to investigate the occurrence of CATSPER-1 in human sperm and whether these channel is involved in human sperm motility and P-stimulated acrosome reaction (AR).

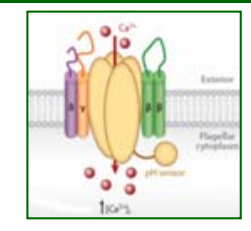

\section{OCCURRENCE AND LOCALIZATION OF CATSPER IN HUMAN SPERM}

\section{Fluorescence Microscopy}

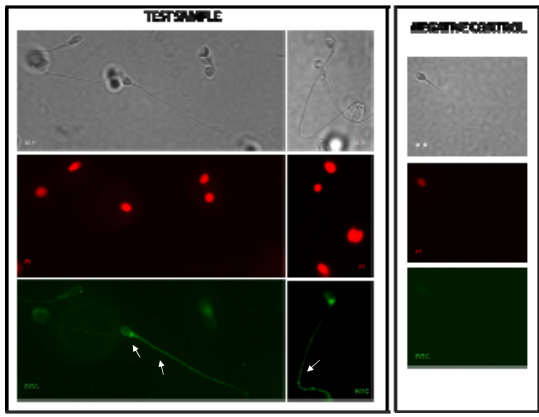

By immunoflorescence we observed that channels are mainly located in the principal piece of the tail

\section{Western Blot}

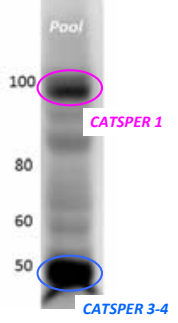

Western blot analysis demonstrated the presence of 2 major bands corresponding to CATSPER 1 and CATSPER 3-4

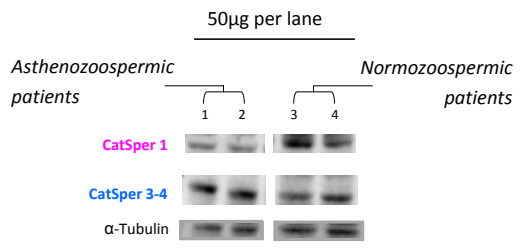

Asthenozoospermic patients show highe expression of CATSPER 3-4 compared to CATSPER on the contrary of normozoospermic patients

\section{ROLE OF CATSPER CHANNELS IN HUMAN SPERM MOTILITY}

Flow Cytometry
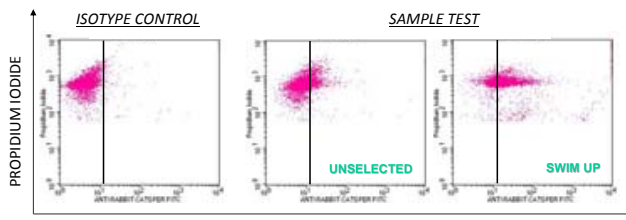

ANTI-CATSPER 1

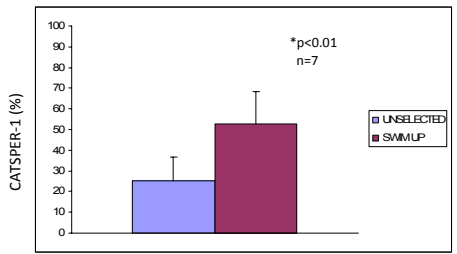

By flow cytometry higher levels of CATSPER were found in swim up selected spermatozoa respect to unselected $(52.7 \pm 15.8$ vs $25.4 \pm 11.1, n=7, p=0.003$ )
C.A.S.A. (COMPUTER ASSISTED SEMEN ANALYSER) =

To investigate the role of CATSPER channels in human sperm motility, we evaluated the effects of the specific inhibitor NNC55-0396 $(10 \mu \mathrm{M})$ and the non specific inhibitor mibefradil $(30 \mu \mathrm{M})$ on swim up selected spermatozoa motility parameters, by using C.A.S.A.
INHIBITORS ADDED TO SELECTED SPERM FOR 15 MIN AFTER CAPACITATION $(n=10)$

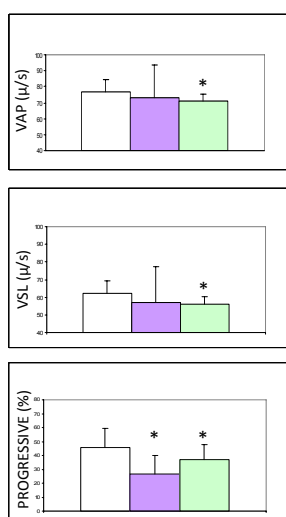

INHIBITORS ADDED DIRECTLY TO SPERM SWIM UP SELECTION MEDIUM $(n=9)$

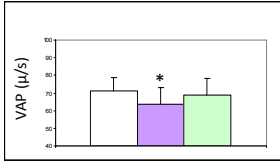

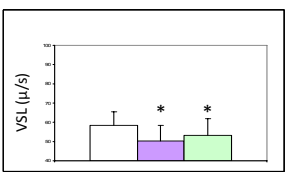

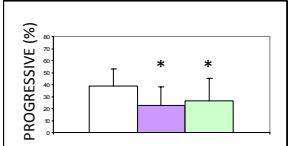

Both compounds significantly inhibited several motility-related parameters.

\section{ROLE OF CATSPER CHANNELS IN P-STIMULATED AR}

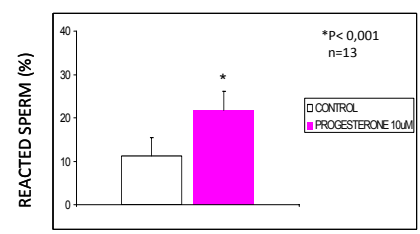

We evaluated the effect of mibefradil $(M)$ and NNC55-0396 (N) on P (10 $\mu \mathrm{M})$-stimulated AR in swim up selected human sperm.

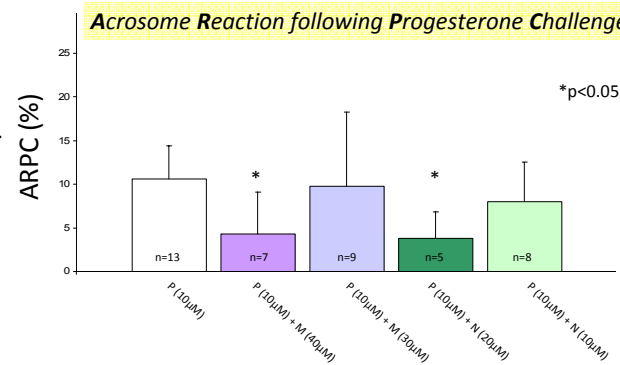

Mibefradil at $30 \mu \mathrm{M}$ was ineffective, whereas a $50 \%$ inhibition was observed at $40 \mu \mathrm{M}$. NNC55-0396 compound, tested at 20 $\mu \mathrm{M}$ concentration, inhibited P induced AR of $70 \%$.

\section{CONCLUSIONS}

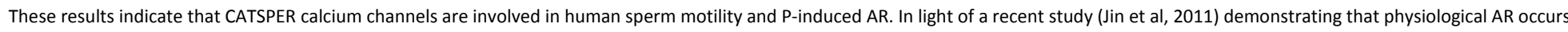

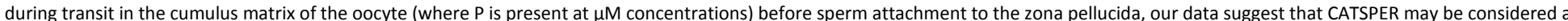
possible molecular target for the development of novel therapeutic strategies for male infertility as well as for male-directed contraception.

\section{REFERENCES}

- Strünker T, Goodwin N, Brenker C, Kashikar ND, Weyand I, Seifert R, Kaupp UB. The CatSper channel mediates progesterone-induced Ca2+ influx in human sperm. Nature. $2011 ; 47: 382-6$. 